\title{
Need for Financial Inclusion and challenges ahead - an Indian Perspective
}

\author{
Sachindra G R \\ Department of Post Graduate Studies in commerce, \\ Rani Channamma University P G Centre Bijapur. India
}

\begin{abstract}
Financial inclusion is delivery of banking services at an affordable cost to the vast sections of disadvantaged and low income group. Unrestrained access to public goods and services is the sine qua non of an open and efficient society. As banking services are in the nature of public good, it is essential that availability of banking and payment services to the entire population without discrimination is the prime objective of the public policy. But in the Existing Banking System segment of the population, especially the underprivileged sections of the society still out of banks' fold. Percentage of adult population having bank account is only $59 \%$, means $41 \%$ of population is unbanked unfortunately this percentage is higher in rural areas. Extent of exclusion from credit markets much more. Number of Loan accounts only $14 \%$ of Adult population and its coverage is only $9.5 \%$ in rural areas. $51.4 \%$ Farm Households have no access to formal or informal sources of credit, $73 \%$ had no access to the formal sources of credit. Considerably, marginal farmers, landless laborers, oral lessees, self employed and unorganized sector enterprises, urban slum dwellers, migrants or ethnic minorities and socially excluded groups, senior citizens and women are out of the purview of financial inclusion. Hence an attempt has been made to analyze the extent of financial inclusion, prevailing lacunas and challenges therein in Indian perspective.
\end{abstract}

\section{Introduction}

The process of economic growth, especially when it is on high growth trajectory, must strive to encompass participation from all sections of society. Lack of access to finance for small/ marginal farmers and weaker sections of the society has been recognized as a serious threat to economic progress especially in developing countries. Moreover, prolonged and persistent deprivation of banking services to a large segment of the population leads to a decline in investment and has the potential to fuel social tensions causing social exclusion.

Financial inclusion means extending basic banking services at affordable prices to the low income and disadvantaged groups. The Purpose of Financial Inclusion is to connect the excluded with the formal banking system in order to help them obtain an understanding of the financial services available and equipping them with the confidence to make informed financial decisions. Rangarajan's committee on financial inclusion defines it as "Financial inclusion may be defined as the process of ensuring access to financial services and timely and adequate credit where needed by vulnerable groups such as weaker sections and low income groups at an affordable cost."

The financial services include the entire range - savings, loans, insurance, credit, payments etc. The financial system has to provide its function of transferring resources from surplus to deficit units but both deficit and surplus units are those with low incomes, poor background etc. By providing these services, the aim is to help them come out of poverty. So far, the focus has only been on delivering credit. It is called as microfinance but is microcredit and has been quite successful. Similar success has to be seen in other aspects of finance as well.

Finance has come a long way since the time when it was not recognized as a factor for growth and development. It is now attributed as the brain of an economic system and most economies strive to make their financial systems more efficient. It also keeps the policymakers on their hand as any problem in this sector could freeze the entire economy and even lead to a infectivity. The earlier research focused on how finance helps an economy. Now, research identifies the importance of financial inclusion. The new avenue for research in finance is - making financial inclusion practical.

Patrick Honohan in his research developed an index to measure access to finance in 160 countries. If the index is put on a world map it can be clearly seen that those economies having higher indices are generally those, which we term as developed economies. It is not obscure that financial inclusion alone has led to the development but is a very important factor with crucial role to play.

The policymakers have set up their committees to understand how financial inclusion can be achieved including advanced economies like United Kingdom. India also set up a committee under the chairmanship of Mr. C. Rangarajan to suggest measures to increase financial inclusion which is hence called the Rangarajan 
Committee on Financial Inclusion. The World Bank had organized a conference in March 2007 and has released a report titled "Finance for All" in November 2007. The report questions that why cannot financial inclusion happen on its own, why there is a need to make number of policies to increase the same, like any other product or service, why can't it find a market of its own, The reasons are -

\section{Financial Exclusion}

It has been found that financial services are used only by a section of the population. There is demand for these services but it has not been provided. The excluded regions are rural, poor regions and also those living in harsh climatic conditions where it is difficult to provide these financial services. The excluded population then has to rely on informal sector i, e, moneylenders, for availing finance that is usually at very expensive rates. It leads to a sadistic cycle. First, high cost of finance implies that first poor person has to earn much more than someone who has access to lower cost finance. Second, the major portion of the earnings is paid to the moneylender and the person can never come out of the poverty.

Lack of knowledge - It can be observed that majority of the people are not aware of the services and facilities available even exclusively for them as they have not came to know the monetary and other benefits that can be derived from them.

High cost - It has also been seen that poor living in urban areas don't utilize the financial services as they find financial services are costly and thus are unaffordable. Hence, even if financial services are available, the high costs deter the poor from accessing them.

Non-price barriers: Access to formal financial services also requires documents of proof regarding a persons' identity, income etc. The poor people do not have these documents and thus are excluded from these services. They may also subscribe to the services initially but may not use them as actively as others because of high distance between the bank and residence, poor infrastructure etc.

Behavioral aspects: Research in behavioral economics has shown that many people are not comfortable using formal financial services. The reasons are difficulty in understanding language, various documents and conditions that come with financial services etc.

The first-ever Index of Financial Inclusion to find out the extent of reach of banking services among 100 countries, India has been ranked 50. Only 34\% of Indian individuals have access to or receive banking services. In order to increase this number the Reserve Bank of India had the Government of India take innovative steps. One of the reasons for opening new branches of Regional Rural Banks was to make sure that the banking service is accessible to the poor. With the directive from RBI, our banks are now offering "No Frill" Accounts to low income groups. These accounts either have a low minimum or nil balance with some restriction in transactions. The individual bank has the authority to decide whether the account should have zero or minimum balance. With the combined effort of financial institutions, six million new 'No Frill' accounts were opened in the period between March 2006-2007. Banks are now considering FI as a business opportunity in an overall environment that facilitates growth.

\section{Financial Inclusion- Need}

It is now widely acknowledged that financial exclusion leads to non-accessibility, non-affordability and non-availability of financial products. Limited access to funds in an underdeveloped financial system restricts the availability of their own funds to individuals and also leads to high cost credit from informal sources such as moneylenders. Due to lack of access to a bank account and remittance facilities, the individual pays higher charges for basic financial transactions. Absence of bank account also leads to security threat and loss of interest by holding cash. All these impose real costs on individuals. Prolonged and persistent deprivation of banking services to a large segment of the population leads to a decline in investment and has the potential to fuel social tensions causing social exclusion. Thus, financial inclusion is an explicit strategy for accelerated economic growth and is considered to be critical for achieving inclusive growth in the country. The following statistics justifies the need for Financial Inclusion

- Indian Economy growing at the rate of $8.5 \%$ to $9 \%$ pa

- Industry and Services contributing most

- Agriculture growing at only $2 \%$

- Limited access to affordable financial services (credit/Insurance/Remittance) behind it.

- To provide access to safe formal payment system savings / Deposit insurance to all

- Provides formal Identity

- Aids social and political stability

\section{Policy Of Reserve Bank Of India On 'Financial Inclusion'}

RBI places a lot of emphasis on financial inclusion to make banks to give desired attention. With proactive role for enhancing the financial inclusion, RBI in its Annual Policy Statement of the year 2005- 2006, 
urged banks to review their existing practices to align them with the objective of financial inclusion. The Reserve Bank of India (RBI) recently said that financial inclusion is not restricted merely to opening of bank accounts and should imply provision of all financial services like credit, remittance and overdraft facilities for the rural poor.

D Subbarao, Governor of RBI said that the accounts must be operational to provide benefits beyond deposit of money like availability of credit, remittance facility and overdraft among others, Though RBI is trying to push the pilot project across the country, it favours learning through intensive experiment in Karnataka. The bank is encouraging all the states to take the financial inclusion process forward. He also refused to forecast the growth rate of Gross Domestic Product (GDP) for the third quarter stating that the RBI will revisit the subject in its January-2012 policy. Declining credit-deposit (CD) ratio, identification of un-banked areas, opening of bank branches in those areas, inadequate flow of credit to agriculture, MSMEs, handicrafts and handloom sectors were cited as areas of concern.

\section{Challenges Of Financial Inclusion In India}

The above research points to the importance of financial inclusion and highlights various policies that have been adopted in India to increase the same. There is another very important point to the entire exercise the spirit of financial inclusion. A few commentators have also pointed to the similarity between sub-prime crisis and financial inclusion. The sub-prime market was originated to provide finance to people with weak credit histories i. e, financial inclusion, enabling them to buy their homes i. e, real sector inclusion. In emerging markets as the population is largely financially excluded some analysts have commented that financial sector need to be careful. The similarity is there but it was more to do with greed in US than the objective of financial inclusion. If the objective were inclusion, then we wouldn't have seen such far-reaching losses in the system. Financial Inclusion has far reaching consequences, which can help many people come out of hopeless poverty conditions. The financial markets must act responsibly and ensure that the spirit of financial inclusion is not breached in the future. The following points witnesses the challenges of financial inclusion in India -

01. Agent and vendor risk.

02. Consumption oriented expenditure patterns.

03. Dormant accounts.

04. Inadequate awareness levels.

05. Lack of infrastructure.

06. Low literacy rates.

07. Measuring actual extent of financial exclusion.

08. Poor saving habits.

09. Recovery related issues.

10. Small ticket transactions \& high transaction costs.

11. Sustainability factor.

12. Varied local conditions.

\section{Conclusions}

Despite the laudable achievements in the field of rural banking, issues such as slow progress in increasing the share of institutional credit, high dependence of small and marginal farmers on non-institutional sources, skewed nature of access to credit between developed regions and less developed regions loom larger than ever before. Therefore, the key issue now is to ensure that rural credit from institutional sources achieves wider coverage and expands financial inclusion. For achieving the current policy stance of "inclusive growth" the focus on financial inclusion is not only essential but a pre-requisite. And for achieving comprehensive financial inclusion, the first step is to achieve credit inclusion for the disadvantaged and vulnerable sections of our society. The state has to play an important role in financial markets. The role itself is necessitated due to pervasive market failures which in the current globalised scenario are not a rare occurrence. In developing countries both market and government as institutions have their limitations, but it is necessary to design government policies that are attentive to those limitations. Financial Inclusion is one such intervention that seeks to overcome the frictions that hinder the functioning of the market mechanism to operate in favor of the poor and underprivileged. One way to proceed towards a solution is to encourage experiments in limited geographical spheres and with select groups of people, under strict monitoring, to see how different mechanisms can work. In addition to satisfying all the characteristics of a credible payment system, these experiments must encourage the excluded from participating in the use of these mechanisms. By incorporating all the above measures process of financial inclusion can achieve the goal of the slogan 'let's connects everyone'.

\section{References}


[1]. Amol Agrawal "The need for Financial Inclusion with an Indian perspective" Economic Research IDBI March 3, 2008

[2]. Financial Intermediation and Growth: Causality and Causes, 2000, Levine,Loayza, Norman, Beck, Thorsten, Journal of Monetary Economics 46.

[3]. Committee on Financial Sector Reforms (Draft Report), 2008, Planning Commission, Government of India.

[4]. Finance for All? Policies and Pitfalls in Expanding Access, World Bank Policy Research Report, 2008, World Bank, Washington

[5]. Financial Development and Economic Growth: Views and Agenda, June 1997, Ross Levine, Journal of Economic Literature, Vol. XXXV.

[6]. The Economics of Microfinance, 2007, Beatrize, Armendariz and Jonathan Morduch, Prentice Hall of India Pvt. Ltd.

[7]. How can Technology Facilitate Financial Inclusion in India? - A Discussion Paper February 16, 2009. 